\title{
A novel therapeutic agent
}

\author{
J. B. Collinson
}

In 1959, quite soon after I joined the oldest of the Scottish Royal Mental hospitals, I was approached by a paranoid lady bearing a jar of "Silver Shred" marmalade, which, she said, was cloudy. She sought my opinion as to whether she should return it to the shop where she had bought it (which I took to be in the town three miles away) or whether perhaps I would care to analyse the jar using the facilities of the laboratory. Unduly eager to avoid any possible trouble with a local shopkeeper, I agreed to take care of the offending jar for the time being.

We must have had some sort of understanding about further exchanges concerning the clouded head of her marmalade, because not long afterwards I received a pencilled note on a fragment of paper, which conveyed the cryptic message that "Since I last had words with thee, my womb has become unstopped, and my ear has begun to run".
By this time I had realised the daily work of the hospital made no allowance for much time being spent exploring the somatic delusions of individuals. The same conclusion must have been reached by my curious patient, because at our last encounter her speech had become a little more garbled, but it was evident that she was prepared to go over my head to appeal to $\operatorname{Dr} A$, the Superintendent. She complained of a vague but irksome trouble with her eyes, and asked if she should approach $\mathrm{Dr} A$ to enquire whether she could have some eyewash.

I was able to reassure her that we did indeed have plenty of eyewash. We parted on good terms, and I like to think, with a fair degree of mutual understanding.

J. B. Collinson, Cartwright Lane, Beverley HU17 $8 L X$ 